\title{
JOVENS ESTUDANTES, INTERDISCIPLINARIDADE E MULTICULTURALISMO: UM ESTUDO EM UMA ESCOLA NO MEIO RURAL
}

\section{YOUNG STUDENTS, INTERDISCIPLINARY AND MULTICULTURALISM: A STUDY IN A RURAL SCHOOL}

\section{Astrogildo Fernandes da Silva Júnior (UFU) silvajunior_af@yahoo.com.br} Leonardo Donizette de Deus Menezes (ESEBA-UFU)

Resumo: Este artigo apresenta resultados de uma prática pedagógica de ensino interdisciplinar desenvolvida em uma escola no meio rural localizada no Distrito de Amanhece, município de Araguari, MG, Brasil. Optou-se por trabalhar uma pedagogia de projeto para assim refletir sobre o multiculturalismo. Para avaliar essa prática pedagógica foi utilizada a técnica do grupo focal. Concluiu-se que, por um lado, o projeto cumpriu o seu papel, pois, envolveu os alunos que procuraram conhecer mais sobre a diversidade cultural. Por outro lado, observou-se que para o sucesso de uma educação multicultural faz-se necessária uma revolução em quatro pontos fundamentais: a) a formação de professores; b) o planejamento dos currículos; c) o desenvolvimento de materiais apropriados; d) a análise e a revisão crítica das práticas vigentes.

Palavras chave: Multiculturalismo. Interdisciplinaridade. educação e juventude.

Abstract: This article represents the results of an interdisciplinary pedagogical practice enrolled in a rural school located at Distrito de Amanhece, Araguari, MG, Brazil. Pedagogical projects were used to reflect about multiculturalism. In order to evaluate this practice a focal group technique was applied. In conclusion, the Project achieved its objective, once it led the students to get knowledge about cultural diversity. On the other hand, it was observed that for a successful multicultural education it is necessary changes in four fundamental points: a) teachers education; b) curricular planning; c) development of appropriated tools; d) analysis and critical revision of ongoing practices.

Keywords: Multiculturalism. interdisciplinary. education. youth.

\section{Introdução}

Neste texto temos como objetivo apresentar e analisar os resultados de uma prática pedagógica de ensino interdisciplinar desenvolvida na Escola Estadual Artur Bernardes localizada no Distrito de Amanhece no município de Araguari, MG, Brasil ${ }^{1}$. Optamos pela pedagogia de projeto para assim refletirmos sobre o multiculturalismo. Comungamos com Veiga (2006) quando defende a relevância do projeto de trabalho

\footnotetext{
${ }^{1}$ Esta escola atende as séries finais do ensino fundamental e o ensino médio. Em decorrência do processo de municipalização, a Prefeitura Municipal de Araguari construiu um outro prédio onde funciona o Centro Educacional Municipal Realino Elias Carrijo, que atende as séries iniciais do ensino fundamental.
}

\begin{tabular}{|l|l|l|l|l|l|}
\hline Interfaces da Educ. & Paranaíba & v. 2 & n. 5 & p.34-45 & 2011 \\
\hline
\end{tabular}


como uma técnica didática centrada na produção de conhecimentos. É uma atividade permeada por intencionalidade na qual o aluno adquire e produz conhecimentos, resolve problemas que o preocupam, sejam eles autênticos ou simulados da vida real.

Ao discutir a educação multicultural, Mclaren (2000) alerta os educadores para a necessidade de incorporar e ir além da política da diversidade. Conforme o autor, o discurso da diversidade e da inclusão é, muitas vezes, predicado com afirmações dissimuladas de assimilação e consenso, que servem como apoio aos modelos democráticos neoliberais de identidade, buscando assimilar as diferenças, tornando a diferença semelhante.

O autor desafia a afirmação aceita de que, para derrotar o racismo, bastam iniciativas a serviço da inclusão de populações minoritárias. Isto, segundo ele, poderá apenas fragmentar a realidade, fazendo com que os indivíduos aceitem, facilmente, viver a mentira de uma sociedade não-racista. Argumenta que é necessário colocar ênfase na análise da etnicidade branca e na desestabilização da identidade branca, especialmente, a ideologia e a prática de sua supremacia.

Nossa proposta foi desenvolver um projeto numa perspectiva interdisciplinar. Fonseca (2005) destaca que a interdisciplinaridade não é apenas uma fusão ou justaposição, mas uma "interpenetração" de conceitos, dados e metodologias, pressupondo, assim, uma integração entre os conteúdos e as metodologias de disciplinas diferentes, que se propõe a trabalhar conjuntamente determinados temas.

\section{O projeto desenvolvido e a opção metodológica}

Nosso intuito de desenvolver um projeto interdisciplinar que proporcionasse reflexões sobre o multiculturalismo não se limitou a uma iniciativa isolada. Mas, a uma proposta integrada que envolvesse toda a comunidade escolar e que fizesse parte do cotidiano da escola. Acreditamos que desenvolver um sentimento, uma atitude e um relacionamento positivo entre os grupos raciais, étnicos, enfim com as diferenças não seja uma realidade dada, e sim uma realidade que deve ser construída e estimulada. Todos os professores se envolveram direta ou indiretamente no projeto. Em primeiro lugar trabalharam textos, canções e aulas expositivas dialogadas com o objetivo de despertar a sensibilidade e a criticidade dos alunos pelo tema. Uma das etapas do projeto culminou em um desfile de moda com os alunos da escola representando a diversidade cultural brasileira e um concurso de desenhos que possibilitou aos alunos expressarem o que compreenderam sobre o multiculturalismo.

Para a realização do desfile, além da participação ativa de todos os professores, contamos também com o apoio de alunas do Curso Design de Moda da Universidade do Triângulo - UNITRI - Uberlândia, $\mathrm{MG}^{2}$. Elas ensinaram os alunos a desfilarem e prepararam a abertura do desfile relacionada com a temática abordada. As universitárias permaneceram na escola por duas semanas trocando ideias com os alunos sobre estilos de roupas e acessórios que realçassem o estilo próprio de cada um. O desfile envolveu toda a comunidade escolar.

\footnotetext{
2 As universitárias Mariana Beatriz da Silva Guirelli e Samanta Ferreira Alves foram parceiras fundamentais para a realização deste projeto. Possibilitaram um crescimento pessoal e profissional para alunos e professores. Para as alunas o projeto contou como estágio para a disciplina Estágio de Moda.
}

\begin{tabular}{|l|l|l|l|l|l|}
\hline Interfaces da Educ. & Paranaíba & v. 2 & n. 5 & p.35-50 & 2011 \\
\hline
\end{tabular}


Com o objetivo de avaliar e reestruturar o projeto, de compreender como as discussões foram incorporadas pelos alunos, e de registrar suas vozes optamos pela metodologia do grupo focal.

A técnica do grupo focal se insere no âmbito das abordagens qualitativas. Nesse tipo de abordagem, o pesquisador aparece de fato como produtor de conhecimento, não como alguém que está acima do objeto cognoscível, mas que interage com ele, influencia e é influenciado. Ocorre uma relação de diálogo, de reciprocidade, sem hierarquização, representando a união entre comunicação e emoção. Entre pesquisador e sujeito a interação ocorre de forma horizontal, especialmente à medida que aceitamos que todos possuem um saber. No Brasil essa técnica vem sendo amplamente usada no campo da educação.

Para a realização do grupo focal estabelecemos como critérios de participação: jovens estudantes do ensino médio, sexo masculino e feminino, brancos, negros, nativos, migrantes e que tivessem participado do desfile de modas que marcou o final dessa etapa do projeto. Esses critérios tiveram como objetivo captar a heterogeneidade e a complexidade dos jovens rurais.

De acordo com Gatti (2005), um grupo focal permite ao pesquisador conseguir boa quantidade de informação em um período de tempo mais curto. Ganha-se em relação à captação de processos e conteúdos cognitivos, emocionais, ideológicos, representacionais, mais coletivos, portanto, menos idiossincráticos e individualizados. Ao possibilitar a exposição ampla de idéias e perspectivas, permite trazer à tona respostas mais completa, assim como verificar a lógica ou as representações que conduzem à resposta. Além do mais, a participação num processo de grupo focal também pode propiciar um momento de desenvolvimento para os participantes, tanto nos aspectos comunicacionais como nos cognitivos e afetivos.

Num primeiro momento, com a técnica do grupo focal, instigamos os jovens a refletirem a seguinte questão: quem é você? Isso nos remete a refletir sobre o conceito de identidade. Deixamos expostas sobre a mesa fotografias do desfile de modas e dos desenhos feitos pelos alunos sobre o multiculturalismo. Além disso, para fomentar discussões sobre o tema utilizamos: uma notícia sobre um índio queimado em Brasília por um grupo de jovens de classe média, fotos que sugerem o homossexualismo, frases para instigar a discussão de gênero, texto sobre preconceito contra nordestinos e sobre justificativas para a escravidão negra no Brasil colônia.

Posteriormente foi realizada a transcrição; feitas a devolução para os participantes; a análise, e, assim a permissão para publicação. Optamos em utilizar o critério de invisibilidade dos estudantes ao adotarmos pseudônimos. Na tabela, a seguir, caracterizamos em linhas gerais, o perfil dos jovens participantes:

Tabela 1 - Perfil dos participantes do grupo focal

\begin{tabular}{l|c|c|l|l}
\hline \multicolumn{1}{c|}{ Nome } & $\begin{array}{c}\text { Idade } \\
\text { (anos) }\end{array}$ & $\begin{array}{c}\text { Ano escolar } \\
\text { (Colegial) }\end{array}$ & Cor & Religião \\
\hline Lúcia & 16 & $2^{\circ}$ & Branca & Católica \\
\hline Fabíola & 17 & $3^{\circ}$ & Parda & Católica \\
\hline Nayane & 18 & $3^{\circ}$ & Branca & Católica \\
\hline
\end{tabular}




\section{INTERFACES DA EDUCAÇÃO}

\begin{tabular}{l|l|l|l|l}
\hline Edson & 16 & $1^{\circ}$ & Branca & Evangélica \\
\hline Ana Maria & 15 & $1^{\circ}$ & Branca & Atéia \\
\hline Evair & 16 & $1^{\circ}$ & Negra & Católica \\
\hline Alessandra & 15 & $1^{\circ}$ & Branca & Católica \\
\hline Marília & 15 & $1^{\circ}$ & Parda & Católica \\
\hline
\end{tabular}

\section{Reflexões sobre as vozes de jovens rurais}

Segundo Carneiro (2005), a categoria juventude rural, que é fluida, heterogênea, imprecisa e variável permanece na invisibilidade nas esferas da vida social, dificultando, assim, a compreensão de sua complexa inserção num mundo culturalmente globalizado. A partir desta afirmação é que nos preocupamos em conhecer um pouco mais sobre a categoria. Sendo assim, o que podemos analisar pelas vozes de jovens rurais acerca do tema multiculturalismo?

Quando instigados a se apresentarem observamos que não podemos afirmar que existe uma identidade fixa, imóvel do jovem rural. Pelo contrário, o que Hall (2005) nos ensina é que não podemos falar em identidade e sim identidades, e que estas são móveis. O autor nos lembra que, mais do que qualquer outra época, esta em que vivemos é caracterizada pela diferença. As sociedades atuais são atravessadas por diferentes divisões e antagonismos sociais que produzem uma variedade de diferentes posições dos sujeitos e diferentes identidades. Segundo Louro (2002), cada sujeito é, ao mesmo tempo, muitas "coisas", tem muitas identidades: de classe, de etnia, de religião, de nacionalidade, de geração, de gênero, etc., e os modos como se articulam essas identidades também são múltiplos. Somos uma mescla de diversas identidades.

Para Silva (2000), a identidade não é essência, não é um dado ou um fato, também não é homogênea, definitiva, acabada, e nem transcendental. É uma construção. As identidades dos jovens rurais, colaboradores desta investigação confirmam esse conflito de identidades. Como exemplos apresentamos duas narrativas:

Fabíola: Nasci em Araguari, mas minha família é paranaense. Identifico-me como paranaense, como mineira, como paulista. Tenho parente no interior de São Paulo, fui lá e gostei muito. Eu moro em uma fazenda a três quilômetros daqui. Gosto muito de lá! É uma casa de madeira, antiga, me identifico muito neste lugar, pois foi lá que nasci. Gosto muito do meio rural, mas estudo para sair de lá, porque o meio rural para mulheres não possibilita grandes oportunidades. Bom, eu me vejo como uma pessoa. Assim, madura pra minha idade. Eu já estou preparando para a faculdade. Meu sonho é me formar, fazer o que eu gosto. Quero jornalismo, gosto muito de falar, de comunicar.

Edson: Nasci em Santa Catarina. Sou filho de pais separados, meu pai mora no estado do Pará e eu fico aqui com minha mãe. Sou evangélico, mas convivo bem com outras religiões, só não conheço ninguém espírita. Não gosto de morar aqui, prefiro a cidade, aqui não tem muito lugar para sair, é só os amigos mesmo. Lá, eu era muito

\begin{tabular}{|l|l|l|l|l|l|}
\hline Interfaces da Educ. & Paranaíba & v. 2 & n. 5 & p.35-50 & 2011 \\
\hline
\end{tabular}


mais envolvido na Lan House, em internet, sinto falta disto. Eu me considero um cara muito brincalhão, assim, levo as coisas na esportiva, mas às vezes sou meio estourado. Qualquer coisa eu apelo dependendo da brincadeira. Vamos supor, falar sobre esse negócio de família eu não gosto. Eu não sou racista, mas faço piadinhas quanto a cor da pele. É eu faço piadinhas, é meio sem graça, mas é difícil de mudar. Eu só estudo, não trabalho e nem tenho namorada. Não gosto de estudar muito não, estudo para passar de ano e depois fazer bagunça. Sou bagunceiro. No futuro eu não quero pensar, porque quando eu penso não dá certo, daí fico assim triste e deixo como está.

Ao analisarmos as vozes dos jovens estudantes que vivem no meio rural podemos perceber a diversidade e isso nos leva a refletir sobre o que vem a ser o meio rural no atual contexto. Segundo Silva Júnior (2007), o rural é uma categoria histórica que se transforma diante dos diferentes momentos, é um espaço diverso, plural tanto nos aspectos sociais e econômicos quanto nos históricos, culturais e educacionais. É um espaço marcado por permanências e transformações.

As transformações podem ser identificadas, por exemplo, quando a aluna Fabíola afirma que o seu tempo está cada vez mais curto, praticamente não fala com os pais, pois estuda de manhã na escola do distrito, à tarde no cursinho preparatório para o Programa de Ação Afirmativa de Ingresso no Ensino Superior - PAIES ${ }^{3}$. O aluno Edson nasceu no Estado de Santa Catarina, filho de pais separados, o pai residia no Estado do Pará, e a mãe na zona rural no município de Araguari, MG. Esses são alguns exemplos que confirmam que o meio rural está inserido no contexto, chamado por Bauman (2004), de modernidade líquida ${ }^{4}$. A modernidade líquida é também caracterizada pela fragilidade, pela fluidez dos laços sociais e pelo não envolvimento dos sujeitos. Segundo o autor,

[...] os lares não são mais ilhas de intimidade em meio aos mares, em rápido resfriamento, da privacidade. Transformaram-se de compartilhados playgrounds do amor e da amizade em locais de escaramuças territoriais, e de canteiros de obras onde se constrói o convívio em conjuntos de bunkers fortificados. 'Nós entramos em nossas casas separadas e fechamos a porta, e então entramos em nossos quartos separados e fechamos a porta. A casa torna-se um centro de lazer multiuso em que os membros da família podem viver, por assim dizer, separadamente, lado a lado' (BAUMAN, 2004, p. 83-84).

Por outro lado podemos afirmar que no meio rural ainda conservam sinais de permanências, pois ao falar da família as alunas Fabíola e Nayane reforçam a importância desta na sua formação:

\footnotetext{
3 O Programa Alternativo de Ingresso ao Ensino Superior - PAIES foi extinto em 2008, e substituído pelo Programa de Ação Afirmativa de Ingresso no Ensino Superior - PAAES, visando ampliar os níveis de inclusão social e de democratização do ingresso no ensino superior. Como podemos encontrar nas resoluções presentes no site $<$ http://www.ingresso.ufu.br/copev/PAAES/inicial.asp> Acesso em 29 jan. 2011.

${ }^{4}$ Bauman, Zygmunt. (2001). Modernidade Líquida. Tradução, Plínio Dentzien - Rio de Janeiro: Jorge Zahar.
}

\begin{tabular}{|l|l|l|l|l|l|}
\hline Interfaces da Educ. & Paranaíba & v. 2 & n. 5 & p.35-50 & 2011 \\
\hline
\end{tabular}


Fabíola: (...) Mas, lá [na sua casa no meio rural] como eu passo o tempo todo com a família, adquiri os costumes da minha família, já incorporei a forma de pensar, o que o meu pai e minha mãe me ensinaram eu costumo usar no meu dia a dia.

Nayane: (...) Gosto de onde moro! você acostuma, você pega o ritmo daquilo ali. Fico pensando se no próximo ano realmente vou fazer uma faculdade... Para eu sair de lá eu vou sentir muito porque eu não vou mais ter colinho de mamãe, não vou mais ter nada disso. Mas levarei comigo o que aprendi com meus pais: a responsabilidade.

Acreditamos que o ensino fundamentado na educação multicultural possa contribuir para despertar o senso crítico dos alunos e, dessa forma, fazer com que valorizem a especificidade do meio rural. É importante lembrar que o ser humano não se resume em ser um consumidor, um ser solitário, auto-referente e autocentrado. E que a história ainda está conosco e pode ser construída.

De acordo com Bauman (2004), a história não terminou e, sendo assim, as escolhas ainda podem ser feitas. Esperamos que alguns valores, como amizade, o diálogo verdadeiramente humano, a solidariedade ainda presentes no meio rural, sejam consolidados e que sirvam de exemplo para minar aspectos negativos da modernidade líquida.

Mostrando fotografias que sugerissem a homossexualidade, instigamos os participantes do grupo focal a manifestarem suas opiniões sobre o assunto. Sobre esse tema houve uma participação ativa de todo o grupo. Dos alunos participantes apenas duas declararam não ter preconceitos. Outros participantes deixaram claro a não aprovação e o preconceito explícito em relação à homossexualidade. Destacamos, a seguir, três narrativas:

Lúcia: Se eu dissesse que concordo estaria sendo hipócrita, porque na verdade não é isso que penso, porque como eu sou católica, a minha religião é o seguinte: nasceu homem, Deus fez homem e mulher, ou seja, os dois para procriar certo? Não sei se é preconceito, acho estranho, diferente, mas se a pessoa preferiu seguir este caminho eu não vou me intrometer. Eu já fui assediada por uma lésbica, foi terrível. Outro fato que eu discordo é das novelas abordarem tanto este fato, isto acaba influenciando as pessoas a tornarem-se homossexual.

Evair: Eu não sou a favor e nem contra homossexuais deixo eles pra lá, no canto deles. Não tenho amigos gays, pelo menos não que eu saiba. Mas não tem problema nenhum converso normalmente, embora acho um pouco diferente. Meu irmão já foi assediado por outro homem dentro do banheiro que é um abuso. No ano passado, na festa de Natal que fazemos em casa, foi um gay, amigo de minha prima. Quando saímos na rua eu procurava ficar longe dele, pois o povo aqui é muito preconceituoso, e falam mesmo.

Alessandra: Se eu falar que não tenho preconceito é mentira, pois todo mundo tem. Se você vê uma mulher beijando outra mulher, você não vai falar que é normal vai? $\mathrm{E}$ a nossa religião não ensinou isso. Ensinou que homem e mulher são para procriar. Para mim é estranho

\begin{tabular}{|l|l|l|l|l|l|}
\hline Interfaces da Educ. & Paranaíba & v. 2 & n. 5 & p.35-50 & 2011 \\
\hline
\end{tabular}


ver mulher beijando mulher e homem beijando homem, não acho isso certo. Só que ver homem beijando homem é mais esquisito, é bem pior.

Essas manifestações são reflexos de uma cultura e, segundo Louro (2002) na nossa sociedade a norma é constituída a partir do homem branco, heterossexual, de classe média urbana e cristã. Todos os outros sujeitos são apresentados tomando-a como referência e como centro. A sexualidade considerada "normal" é a heterossexual. Homens e mulheres homossexuais ou bissexuais estão fora da norma, são tidos como desviantes, doentes ou pervertidos. De acordo com as narrativas das alunas Lúcia e Alessandra esse fato é reforçado pela igreja. Pelo registro do jovem Evair o preconceito no meio rural é intenso.

As vozes dos alunos servem de alerta para compreendermos que a questão da sexualidade não pode mais se limitar "a quatro paredes". Educadores que se pretendem críticos não devem se permitir a uma posição de ignorância ou desatenção face a tudo isso. Tácito.

De acordo com Louro (2002) as nossas escolas parecem propor um acordo tácito de silêncio, dissimulação e negação a respeito da sexualidade. Estudantes e professores deixam de fazer perguntas, disfarçam curiosidades e inquietações, deixam transparecer a falsa impressão que todos vivem de acordo com os padrões estabelecidos.

O debate em torno da sexualidade, de orientações sexuais se torna cada vez mais necessário. Nos últimos anos, as discussões sobre o tema ampliaram-se, tendo conseguido ocupar espaço em muitas escolas e até mesmo integrar os Parâmetros Curriculares Nacionais - PCNs. Nesse sentido questionamos: os professores compreendem a importância dessa questão? Estão preparados para mediar esse debate? Segundo Louro (2002), os adultos têm dificuldades em lidar com sua própria sexualidade e acabam por produzir uma muralha de constrangimento e omissão. Esse fato nos instiga outro questionamento: se o professor tem dificuldades de lidar com sua própria sexualidade como ajudar seus alunos nessa questão?

Concordamos com Louro (2002) ao afirmar que as práticas escolares e os currículos, além de transmitir representações sociais também produzem essas representações sobre a sexualidade. Sendo assim, o silenciamento em torno das "novas" identidades sexuais se constitui numa forma de representá-las, na medida em que as marginaliza e as deslegitima. O silêncio confirma a tomada de posição ao lado de quem já detém a autoridade.

Quanto ao gênero, os alunos foram unânimes em defender a posição de igualdade entre mulheres e homens. Talvez pela maior participação de mulheres no grupo focal. Mas, houve algumas manifestações em que foi possível identificar algumas contradições. Por exemplo, o aluno Evair afirmou que homens e mulheres devem ter direitos iguais. Mas quando ele se apresentou no início da nossa reunião o estudante afirmou:

Evair: Não trabalho em casa, afinal tem minha mãe e minha irmã. Lá em casa, os homens ficam tranquilos e as mulheres trabalham.

A aluna Ana Maria também se manifestou de forma contraditória, para ela a mulher pode fazer qualquer tipo de trabalho, menos participar da política. Acreditamos que isso não representa um preconceito para a aluna, no sentido de que as mulheres são

\begin{tabular}{|l|l|l|l|l|l|}
\hline Interfaces da Educ. & Paranaíba & v. 2 & n. 5 & p.35-50 & 2011 \\
\hline
\end{tabular}


incompetentes na política. Mas, a política que não é digna de ter mulheres dela participando. As marcas de nosso tempo reforçam a decadência da popularidade do engajamento político em que o espaço público, segundo Bauman (2001), está cada vez mais vazio de questões públicas. Isso serve de alerta para nossos representantes políticos, pois, tanto os eleitores como os políticos mais cedo ou mais tarde se encontrarão novamente e, sendo assim, a credibilidade deve ser o recurso mais valioso destes. Talvez, as recentes conquistas da mulher no cenário político brasileiro ajude na construção da necessidade de uma maior participação da mulher na vida política.

Esse pode ser mais um desafio para os professores: incentivar a participação política dos jovens brasileiros e, nesse caso em especial, dos jovens rurais. É necessário também contribuir para a formação politizada de cidadãos e futuros políticos dignos de nossa confiança.

O Brasil foi construído com uma base multicultural muito forte. Segundo Candau (2002), as relações interétnicas têm sido uma constante ao longo da nossa história, uma história dolorosa principalmente aos grupos indígenas e afrodescendentes. Nossa formação histórica está marcada pela eliminação física dos "estranhos", , ou pela escravização ou pela negação da cultura.

Para fomentar a discussão sobre a questão indígena apresentamos uma reportagem sobre um índio queimado por jovens de classe média em Brasília. A reação dos participantes foi de indignação. Porém, observamos que os alunos não aprofundaram a discussão sobre a importância, a especificidade da cultura indígena. Limitaram-se em rejeitarem a atitude dos jovens que praticaram o crime.

Com o objetivo de instigar o debate sobre o negro no Brasil apresentamos documentos de meados do século XIX que buscavam justificar a escravidão. Segundo os documentos a igualdade não se aplica a todos os homens e quem defende isso é impostor e hipócrita; a liberdade é um direito que, se fosse concedido a um bruto selvagem, como o negro, se transformaria em uma arma perigosa e forjada para o ódio contra as famílias; a liberdade, diziam, entregue à massa escrava, implicaria perturbação da ordem pública, pois os escravos, devido à sua inteligência embotada, não estariam preparados para a vida em liberdade (MAGALHÃES, 2003).

Todos os alunos, participantes do grupo focal, se mostraram indignados com as justificativas apresentadas. Afirmaram não terem preconceito racial. A aluna Nayane declarou que preferia ter a pele mais escura. Fabíola disse que é fascinada pela cultura negra, especialmente a capoeira. Lúcia relembra que dava aulas de computação para crianças negras e se sentia muito bem. Uma análise menos crítica sobre as manifestações dos alunos pode confirmar uma verdadeira democracia racial, mas ao interpretar as "entre linhas" dos discursos percebemos que a visão dos participantes em relação ao negro é de percebê-los como exótico.

O aluno Edson se posicionou de maneira ambígua, no mínimo curiosa:

Edson: Eu não tenho preconceito, para mim todos são iguais, mas eu gosto de fazer "piadinhas" sobre o negro, mas não é preconceito é apenas "zoação".

Também nos chamou a atenção, a participação do aluno Evair:

Evair: (...) quanto a minha etnia eu não sei, é uma mistura muito doida. A família da minha mãe é inteirinha branquinha, a do meu pai é

\footnotetext{
${ }^{5}$ Termo utilizado por Bauman ao se referir aos grupos minoritários, os outros, os diferentes.
}

\begin{tabular}{|l|l|l|l|l|l|}
\hline Interfaces da Educ. & Paranaíba & v. 2 & n. 5 & p.35-50 & 2011 \\
\hline
\end{tabular}


inteirinha negrinha. Ai nessa mistura ficou nós, a gente não é tão escuro feito a família do meu pai e não tão claro feito a família da minha mãe. Considero-me moreno.

Evair é um rapaz negro, porém não se identifica como tal. O que nos desperta preocupações, como educadores, em fazer presentes nos currículos e nas práticas pedagógicas, a consciência da identidade cultural e social, o autoconceito, a autoestima, o combate ao racismo, ao preconceito e à discriminação cultural e social.

Para que o negro e o índio elevem sua auto-estima torna-se imperioso reescrever o conhecimento, a partir de cada um dos grupos étnicos que constituem a nação. Dessa forma, conhecerão uns aos outros nas suas diferenças, não ficando a maioria instalada a abandonar as suas raízes culturais mais fecundas e assumir uma outra que lhe é alheia (SILVA, 1998).

Como afirmamos na introdução deste artigo, a Escola Estadual Artur Bernardes, na qual desenvolvemos o projeto, é um espaço também caracterizado pela migração. Os "migrantes econômicos", expressão utilizada por Bauman (2004), deixam seus estados e assim tentam encontrar formas de subsistência onde elas podem ser encontradas, em vez de ficarem onde não existem. São expulsos de suas terras, catapultados para outras regiões, condenados ao nomandismo. Neste caso, são mais comuns os nordestinos que chegam ao município fugindo da miséria e da fome.

É também comum outro tipo de migração, a saber, as famílias que chegaram à região, compraram um pequeno pedaço de terra e desenvolvem a agricultura familiar. Esses migrantes são provenientes dos estados do sul do Brasil, especialmente do Paraná.

Como a migração é um fenômeno marcante no município de Araguari-MG, estimulamos o debate sobre esse assunto utilizando dois textos que mostram o preconceito contra os nordestinos. A aluna Lúcia manifestou-se da seguinte maneira:

Lúcia: Meu caso é muito engraçado porque a minha avó não é filha de nordestino, não tem sangue nordestino. Só que foram morar no Ceará. O meu avô veio de Portugal, conheceu minha avó e depois de casados foram morar em São Paulo. Então tiveram assim, no início, muito preconceito apesar dela ser branca, de não ter nenhum traço nordestino. Só que mesmo assim houve preconceito porque ela morou no Ceará, mesmo ela não tendo nascido lá, e sim no Rio Grande do Sul e meu avô de Portugal.

É possível observar na narrativa da participante o quanto ela valoriza a descendência portuguesa do avô e reforça que sua avó não tem nenhum traço nordestino dizendo que ela é do Rio Grande do Sul. Assim é possível concluir que existe o preconceito, embora não assumido. A aluna Fabíola afirmou que não tem problemas com nordestinos, inclusive seu pai sempre emprega "baianos" para o trabalho temporário na lavoura. Segundo a aluna eles são "bons de serviço", mas têm um problema: "bebem muita cachaça".

Por mais que não seja explícito, o preconceito contra os migrantes nordestinos é uma realidade na escola. Vir do Sul significa uma aceitação rápida pelos colegas, como foi o caso do aluno Edson que nasceu no Estado de Santa Catarina. Os alunos migrantes nordestinos não têm a mesma aceitação.

\begin{tabular}{|l|l|l|l|l|l|}
\hline Interfaces da Educ. & Paranaíba & v. 2 & n. 5 & p.35-50 & 2011 \\
\hline
\end{tabular}




\title{
Considerações finais
}

Ao fazermos uma retrospectiva sobre o projeto interdisciplinar e questionarmos sua validade podemos ter respostas positivas se levarmos em consideração a modesta pretensão inicial que era possibilitar reflexões sobre o multiculturalismo. Foi possível perceber um envolvimento da maioria dos alunos no projeto. Os estudantes exercitaram a autonomia, pois pesquisaram sobre a diversidade cultural brasileira. Houve sugestões para a continuação do projeto, como a apresentação de uma feira cultural.

Por outro lado, o trabalho realizado possibilitou uma autocrítica e podemos afirmar que estamos ainda distantes de uma educação multicultural. Para efetivar esse tipo de educação Sacristán (1995), nos ensina que é preciso também introduzir nos conteúdos curriculares ou mesmo nos livros didáticos uma perspectiva multicultural. Não devemos apenas contentar em introduzir alguns temas a mais. Para o autor um currículo multicultural implica em mudar não somente as intenções do que queremos transmitir, mas os processos internos que são desenvolvidos na educação institucionalizada.

Os materiais didáticos, em especial o livro didático, o mais comum, se não o único aos quais os alunos das escolas públicas do meio rural têm acesso, não representam as perspectivas culturais dos grupos que compõem uma sociedade multicultural.

Outro fato nos chamou a atenção: os meios de comunicação, principalmente a televisão, que apresenta em determinados programas, em especial de humor, uma visão, na maioria das vezes preconceituosa em relação às diferenças ${ }^{6}$. Na medida em que a educação escolarizada não intervir na crítica e depuração desse conhecimento social extra-escolar ela não se torna ativa em um âmbito de socialização, decisivo para os indivíduos. Segundo Sacristán (1995),

\begin{abstract}
Ressaltar o valor e a força do currículo extra-escolar deve servir para os educadores moderarem as expectativas de seu poder de intervenção a partir da escola, fazendo com que a perspectiva multicultural seja formulada a partir de coordenadas mais amplas que as do currículo escolar, com frentes de atuação muito diversas, e com que se proponham estratégias didáticas que vinculem o conhecimento escolar relativo ao tema que nos ocupa com as aprendizagens de origem externa à escolaridade (SACRISTÁN, 1995, p. 90-91).
\end{abstract}

As vozes dos alunos sobre alguns temas que fazem parte de uma educação multicultural, trabalhados nessa investigação, revelaram o grande desafio que nós, professores, temos pela frente. Além de trabalhar os conteúdos de uma cultura básica comum a serviço da igualdade de oportunidades, faz-se necessário "empoderar" os estudantes de forma que se percebam como importantes agentes sociais para que possam atuar no mundo social, cientes de suas potencialidades, de seus direitos e de seu poder. Enfim, possibilitar aos alunos adquirirem habilidades, conhecimentos para

\footnotetext{
${ }^{6}$ FRANCO, Alexia Pádua. Ensino de História, Televisão e Pluralidade Cultural: (Re) pensando relações. 1998. Dissertação (Mestrado em Educação). Faculdade de Educação, Universidade Federal de Uberlândia, Uberlândia, MG.
}

\begin{tabular}{|l|l|l|l|l|l|}
\hline Interfaces da Educ. & Paranaíba & v. 2 & n. 5 & p.35-50 & 2011 \\
\hline
\end{tabular}


conviverem em paz e harmonia com o devido respeito aos diferentes grupos de nossa sociedade plural.

Embora todos os professores tenham tido boa vontade em participar desse projeto interdisciplinar, constatamos a dificuldade de muitos docentes em relacionar seus conteúdos com as atividades extra-classe, principalmente os professores da área das exatas. Entendemos que trabalhar sobre multiculturalismo de forma isolada, e em datas esporádicas tende a ser uma medida paliativa ou tão somente um trabalho com placebos.

A partir dessas análises é possível reforçar os ensinamentos de Sacristán (1995). Segundo esse autor para o sucesso de uma educação multicultural são fundamentais mudanças nos seguintes setores: a) a formação de professores; b) o planejamento dos currículos; c) o desenvolvimento de materiais apropriados; d) a análise e a revisão crítica das práticas vigentes.

Ao refletirmos sobre as manifestações dos estudantes que participaram do grupo focal, podemos afirmar que se pretendermos uma educação multicultural transformadora, reforçamos que não devemos nos contentar com discussões esporádicas e pontuais e em apenas alguns conteúdos. Assim como mudar o currículo, acreditamos que é importante transformar as atitudes em sala de aula. Isso nos leva a questionamentos: As questões referentes ao multiculturalismo perpassaram a formação inicial dos professores? Entendemos que a formação dos professores tem sua origem formal nos cursos de formação inicial e que deve se estender para o ambiente de trabalho mediante ações de formação continuada. Como essa educação continuada se efetiva na realidade das escolas rurais?

Além de questionar sobre a formação inicial e continuada dos professores, pois sabemos que estas não são as únicas responsáveis pelas mazelas da educação escolar, pontuamos outros questionamentos: quais as condições de trabalho dos professores em escolas no meio rural? E o salário? E a jornada de trabalho? Existe autonomia profissional? Qual a situação dos prédios escolares onde trabalham? Como as políticas públicas interferem no trabalho das escolas rurais?

São questões que nos instigam a continuar nossa investigação sobre a educação escolar no meio rural. Não podemos perder o espírito de luta. Acreditamos na importância de persistir na empreitada por uma educação que possibilite a interação, o envolvimento das diferenças que compõem nossa sociedade.

Se o valor mais precioso do ser humano é uma vida de dignidade e não de sobrevivência a qualquer custo, acreditamos que os professores possam contribuir por uma sociedade mais justa, mais igual ao reforçar em suas atitudes cotidianas a luta pelos direitos iguais quando a diferença inferioriza e pelo direito de ser diferente quando a igualdade os descaracteriza. Concordamos com Silva e Fonseca (2007, p. 55), ao afirmarem que para combatermos os discursos etnocêntricos, conservadores e preconceituosos implícitos ou explícitos nos discursos curriculares, nos meios de comunicação de massa e nos materiais didáticos, devemos valorizar permanentemente as vozes dos diferentes sujeitos, o diálogo, o respeito à diferença, o combate à desigualdade e o exercício da cidadania.

\section{Referências Bibliográficas}

BAUMAN, Zygmunt. Amor Líquido. Rio de Janeiro: Jorge Zahar Editora, 2004.

\begin{tabular}{|l|l|l|l|l|l|}
\hline Interfaces da Educ. & Paranaíba & v. 2 & n. 5 & p.35-50 & 2011 \\
\hline
\end{tabular}


BAUMAN, Zygmunt. Modernidade Liquida. Rio de Janeiro: Jorge Zahar Editora, 2001. CANDAU, Vera Maria Ferrão. Sociedade, Cotidiano Escolar e Cultura(s): Uma Aproximação. Educação \& Sociedade. V. 23. n. 79 Campinas, SP, 2002.

CARNEIRO, Maria José. Juventude rural: projetos e valores. In: ABRAMO, H. W., BRANCO, P.P.M. Retratos da juventude brasileira. Instituto Cidadania e Editora Fundação Perseu Abramo, São Paulo, 2005.

FONSECA, Selva Guimarães. Didática e Prática de Ensino de História. Campinas SP: Papirus, $3^{\text {a }}$ edição, 2005.

FRANCO, Alexia Pádua. Ensino de História, Televisão e Pluralidade Cultural: (Re) pensando relações. Dissertação (Mestrado em Educação). Faculdade de Educação, Universidade Federal de Uberlândia, Uberlândia, MG, 1998.

GATTI, Bernardete Angelina. Grupo focal na pesquisa em ciências sociais e humanas. Brasília: Líber Livro Editora, 2005.

HALL, Stuart. A identidade cultural na pós-modernidade. Trad. Tomaz Tadeu da Silva, Guaracira Lopes Louro. 10. ed. Rio de Janeiro: DP\&A, 2005.

LOURO, Guacira Lopes. Currículo, Gênero e Sexualidade. Porto Editora. Porto, 2002.

MAGALHÃES, Gustavo Celso de. História: $7^{\mathrm{a}}$ série - ensino fundamental. Belo Horizonte: Editora Universidade (Coleção Pitágoras), 2003.

MCLAREN, Peter. Multiculturalismo Revolucionário. Porto Alegre: Editora Artmed, 2000.

SACRISTÁN, Gimeno J. Currículo e Diversidade Cultural. In: SILVA, Tomaz Tadeu. MOREIRA, Antônio Flávio (Org.) Territórios contestados: o currículo e os novos mapas políticos e culturais. Petrópolis, RJ: Vozes, 1995.

SILVA JÚNIOR, A. F. Saberes e Práticas de Ensino de História na Educação Escolar no Meio Rural: Um estudo no município de Araguari, MG. Dissertação (Mestrado em Educação). Faculdade de Educação, Universidade Federal de Uberlândia, Uberlândia, MG, 2007.

SILVA, Marcos. FONSECA, Selva Guimarães. Ensinar História no século XXI: Em busca do tempo entendido. Campinas, SP: Papirus, 2007.

SILVA, Petronilha Beatriz Gonçalves. Espaços para educação das relações interétnicas: contribuições da produção científica e da prática docente, entre gaúchos, sobre negro e educação. In: SILVA, Luiz Heron. A escola cidadã no contexto da globalização. Editora Vozes, Petrópolis, 1998.

SILVA, Tomaz Tadeu da. Identidade e diferença: a perspectiva dos estudos culturais. Tomaz Tadeu da Silva (Org.). Stuart Hall, Kathryn Woodward. - Petrópolis, RJ: Vozes, 2000.

VEIGA, Ilma Passos Alencastro. Projeto de ação didática: uma técnica de ensino para inovar a sala de aula. In: VEIGA, Ilma Passos Alencastro (Org.). Técnicas de ensino: Novos tempos, novas configurações. Campinas, São Paulo: Papirus, 2006.

\begin{tabular}{|l|l|l|l|l|l|}
\hline Interfaces da Educ. & Paranaíba & v. 2 & n. 5 & p.35-50 & 2011 \\
\hline
\end{tabular}

